\title{
Research on the Development Strategies of Rural Tourism in China
}

\author{
Ting Zhao ${ }^{1}$ \\ ${ }^{1}$ School of Finance and Economics, Qinghai University, Xining City, Qinghai Province, \\ 810000
}

Keywords: Rural tourism, Significance, Development ways

\begin{abstract}
To develop rural tourism is an important way to promote economic and social development of rural areas in China. With the rapid development of rural tourism in China, a successful development model of rural tourism in a region has forward-looking, scientific and strategic guidance. Based on the author's learning and practical experience, this paper analyzes the basic types of rural tourism, discusses the significance of the development of rural tourism, and proposes development strategies of rural tourism with Chinese characteristics on the basis of all analyses.
\end{abstract}

\section{Introduction}

Rural tourism is also known as agricultural tourism, sightseeing agriculture, green tourism, rural tourism, ecotourism and so on, which relies on a sound natural environment and cultural landscapes in rural areas. This kind of tourism takes advantage of agricultural activities, rural idyllic scenery, specialty of village culture and local ethnic customs to attract urban residents who are the main target market. Farmers, the main body of the market, make use of differences in the natural landscapes, customs and culture between urban and rural areas to produce tourism products through innovative, planning and design, and the combination of tourism resources. The goal is to provide tourism activities with sightseeing visit, leisure, sports, entertainment, learning and shopping integrated together for urban residents.

\section{Basic Types of Rural Tourism}

The first one is natural scenery tourism, which includes various tourism activities relaying on the natural scenery in the country, such as country walks, hiking, skiing, horseback riding, boating, rafting and so on. The second is town tourism or farm tourism, including leisure farms, which is a type of sightseeing tourism. This type takes green landscapes and idyllic scenery as its subject. The picturesque scenery and blue sky make visitors enjoy themselves so much and forget to leave. Moreover, the elegant, quiet, comfortable, pleasant and green space is the best choice for people to return to nature. The third one is rural folk tourism and national customs tourism. The rural folk tourism attracts outside tourists by everyday life and folk culture in the local place. From the perspective of living space, it can be divided into folk tourism in mountain villages, watery places and fishing villages. From the view of the nature of products, it can be divided into sightseeing tourism, participative tourism, and leisure tourism. The fourth is rural participative tourism, where you can pick flowers or fruits and taste delicious food. For example, you can appreciate flowers and pick fruits in orchards and visit, taste or purchase specialties on the featured street. All of these have boundless attraction to visitors. Farmers will open orchards, vegetable gardens, flower gardens and tea gardens where fruits have been mature. Visitors are allowed into these gardens to pick fruit, vegetables, flowers and tea, and enjoy the fun in rural areas. This is the most popular agricultural 
tourism at home and abroad. The last one is educational rural tourism which aims to broaden people's horizon and increase their knowledge such as rural tourism areas and educational farms that integrate knowledge, investigation, learning and entertainment together. This kind of rural tourism combines agricultural production and scientific education together.

\section{The Significance of Developing Rural Tourism}

To overcome the contradiction between off season and high season in tourism industry. Rural tourism is a combination of agriculture and tourism. To a certain extent, it overcomes the contradiction between off season and high season in traditional tourism industry. In off-season, rural tourism gives priority to agricultural production, and turns to service-oriented tourism in high season. The operational core should be converted with the change between off season and high season. This will conquer the problem of seasonal differences in traditional tourism and the tourism can take full and reasonable advantage of people, finance, materials and other resources.

To help to increase farmers' income. Using these resources to develop rural tourism will attract local farmers to participate in the tourism service industry, such as catering, accommodation, transportation and the cultivation, processing and marketing of local products. They will provide services for tourists directly or indirectly and gain substantial income directly. In addition, as more tourists personally involve in picking fruits and tasting agricultural products which are purchased locally. This will reduce marketing sections of agricultural products, lower transaction costs and improve farmers' income indirectly.

To provide employment opportunities for the surplus rural labor force. To develop rural tourism is an important measure to build a new socialist countryside. Tourism itself is a labor-intensive industry which has a strong absorptive capacity of labor force. Rural tourism transfers a majority of farmers to non-agricultural fields. To develop rural tourism and tourism resources needs one-stop services facilities, which require not only administrative staff, but also a lot of service personal. That means the development of tourism resources can absorb a mass of labor force.

To be conducive to readjustment of agricultural structure. Rural tourism promotes the construction of modern agricultural economic system, and accelerates the development of scientific and technological agriculture, sightseeing agriculture and ecological agriculture, which optimizes and adjusts the structure of rural undertaking. The core of construction of socialism new countryside is to change the growth pattern of rural economy and transfer agricultural labor force into non-agricultural industries through readjusting the employment structure and changing rural economic growth pattern. In order to develop rural tourism, processing the agricultural production, rural styles and farmers' working life into tourism products and bringing them to market will give full play to the function of agricultural tourism. This will promote the adjustment of agricultural structure, broaden the connotation and denotation of agricultural development, create new growth point for the development of rural economy, and achieve the goal of development and construction of new countryside.

To help to narrow the gap between urban and rural areas and speed up the process of city and countryside integration. At present, China has entered a new development stage with industry re-feeding agriculture, promoting agriculture through industry and rural areas driven by urban areas. The development of rural tourism meets the need of residents' consumption structure upgrading, achieves the goal to connect large-scale agriculture with grand tour and speeds up the development of the integration between rural and urban economies and interactive development of the three main industries. This not only increases urban residents' consumption in rural areas, but also accelerates 
the flow of information, finance technology and other resources to rural areas. The development of rural tourism resources can increase opportunities for urban and rural residents to contact and have mutual understanding with each other. This will also significantly improve sanitation and village appearance in rural area, and enhance farmers' ideology and civilization. The development of rural tourism is an important way to develop the rural areas driven by the urban areas.

\section{The Development Strategies of Rural Tourism with Chinese Characteristics}

Various new tourism trends, the emergence of new demand and especially the proposal of the concept of Beautiful China give birth to fresh tourism thoughts and models. The existing development model of rural tourism cannot match the law of its own development. The concept of Beautiful China advocates green, low-carbon, and cyclic development, and the path of sustainable development. Therefore, we should add ecological elements into the traditional development model of tourism and build new development model of tourism from the view of the support of tourism resources, the main body of market and the theme of product items to meet the needs of rural tourism in the new situation.

Innovate the base of tourism resources.In most parts of China, the development of rural tourism usually relies on three traditional resources, rural areas, agriculture and farmers, which has led to a lot of similarities in tourism resources and more homogenization in tourism products. Therefore, we must tap the cultural connotation of traditional resources and cultivate new tourism resources, especially green and eco-tourism resources. The core competence of rural tourism is the original and authentic rural culture. The rural tourism culture is rooted in contacts, geographical identity and the cultural context, which are consistent with nature, culture and history in rural areas. Therefore, to tap the cultural connotation of rural culture is the key to the sustainable development of rural tourism. New tourism resources include relying-on-technology and relying-on-festival types. The relying-on-technology type mainly makes use of modern technology and industry convergence to create rural tourist landscapes, such as the real Happy Farm. The relying-on-festival type is to scheme tourism festivals, such as the Pumpkin Day, Strawberry Festival, Cherry Festival, Garlic Festival, Hamburg Festival and other rural tourism festivals in the United States, which provides a reference for innovative development of rural tourism in China.

Expand the bodies of development and management. Development of rural tourism should choose the most appropriative management form based on local conditions to achieve all-win under the premise of protecting the interests of rural residents. Most existing bodies of the development and management of rural tourism are the government or enterprises. Farmers just participate in some activities. Therefore, we should develop farmers into the body and give full play to the community participation. We can follow the example of France to build Farmers + Enterprise + Community + Government model. The development of rural tourism must be planned reasonably with sustaining original rural scenery. Taking farmer as the main body can guarantee the sustainability and authenticity. Enterprises, as a support system, should provide funds and management philosophy for the development of rural tourism. Under the policy guidance of the government, associations formulate industry and quality standards for rural tourism, promote self-regulation, and play an important part in sustainable development of rural tourism. The government should regulate industry market from the perspective of laws and provide preferential policies for rural tourism.

Enrich themes of product items. Rural tourism products should attach importance to authenticity, experience, diversity, the innovation of which mainly reflects on the innovation of forms, types and functions. The innovation of forms mainly embodies in the rural characteristics 
and creating rural experiential projects. For example, Wuzhen dyeing workshops in Jiangnan allow tourists to participate in the cloth production process; we can also refer to French wine chateau and tourists can know brewing technique, the wine culture and its history by visiting vineyards and workshops, and participating in the whole process of winemaking. The innovation of types is to build a new development model of products based on existing tourism resources and market dynamics. We can take example by Spanish Castle Village Hotel and Singapore's Agricultural Science and Technology Park. The innovation of functions is to tap and develop functions of rural tourism to meet the changing consumer demand of tourists. Tourism products should reflect ecology in addition to the interaction, culture and characteristics. Therefore, we should pay attention to protecting the rural environment when innovate products. Recreational tourism products should try to provide low-carbon activities, such as providing low-carbon trees which tourists can plant, thus increasing its entertainment.

\section{Conclusion}

Rural tourism has been a top topic in tourist market in 21 century and the concept of Beautiful China lays a theoretical foundation for the stable and sound development of rural tourism. Building a sustainable development model of rural tourism is beneficial to maximizing the effectiveness of pro-poverty tourism and has strategic and forward-looking guidance for the development of new rural construction and rural tourism. The construction of development model of rural tourism is sustainable, dynamic and market-oriented.

\section{References}

[1] Zhang Shumin, Zhong Linsheng, Wang Lingen. The Discussion on the Development Model of Rural Tourism in China from the Perspective of Tourism System Theory [J]. Geographical Research, 2012,11: 2094-2103.

[2] Ma Yong, Zhao Lei, Song Hong, Guo Qingxia, Liu Mingjian. The Development Path and Pattern of Rural Tourism in China - A Case Study of Development Model of Rural Tourism in Chengdu [J]. Economic Geography, 2007,02: 336-339.

[3] Guo Huancheng, Han Fei. A Review on the Development of Rural Tourism in China [J]. Advances in Geographic Sciences, 2010,12: 1597-1605.

[4] Li Deming, Cheng Jiumiao. Development Models and Countermeasures in Sustainable interaction between Rural Tourism and Economy [J] Human Geography, 2005,03: 84-87.

[5] Huang Haihui. The Development Model of Rural Tourism in Developed Countries and Regions [J]. Heilongjiang Foreign Trade, 2011,06: 112-114.

[6] Wei Wei, Wang Jinye. The Research on Development Pattern and Operation Mechanism of Rural Tourism - A Case Study of Five Golden Flowers in Chengdu [J]. Rural Economy, 2009,07: 80-83. 